\title{
Lactose oxidase: A novel activator of the lactoperoxidase system in milk for improved shelf life
}

\author{
Sofía Lara-Aguilar and Samuel D. Alcaine* \\ Department of Food Science, Cornell University, Ithaca, NY 14853
}

\section{ABSTRACT}

The lactoperoxidase system (LS), an antimicrobial system naturally present in milk that is activated by $\mathrm{H}_{2} \mathrm{O}_{2}$, has been used to inhibit microbial outgrowth in raw milk in areas where refrigeration is not viable. This study evaluated lactose oxidase (LO) as a novel activator of the LS. Lactose oxidase oxidizes lactose and produces $\mathrm{H}_{2} \mathrm{O}_{2}$ needed for the activation of the LS. The antimicrobial effect of different concentrations of LO with and without components of the LS, thiocyanate (TCN) and lactoperoxidase (LP), was evaluated in model systems and then applied in pasteurized milk and raw milk. In general, an increase in LO caused greater reductions of Pseudomonas fragi in the model systems and treatments were more effective at $6^{\circ} \mathrm{C}$ than at $21^{\circ} \mathrm{C}$. At $6^{\circ} \mathrm{C}$, the $\mathrm{LO}$ solution at 0.12 and $1.2 \mathrm{~g} / \mathrm{L}$ showed significantly higher microbial reduction than the control when both added alone and combined with LS components. At $21^{\circ} \mathrm{C}$, treatments with $1.2 \mathrm{~g} / \mathrm{L}$ of LO solution achieved a reduction of $>2.93 \mathrm{log} \mathrm{cfu} / \mathrm{mL}$ in $24 \mathrm{~h}$, but at lower levels there was not a significant reduction from the control. Higher concentrations of TCN led to a greater $P$. fragi reduction at both temperatures when LO was added alone but not when combined with LP. In pasteurized milk, the LO solution at $0.12 \mathrm{~g} / \mathrm{L}$ caused a reduction of approximately $1.4 \mathrm{log}$ of $P$. fragi within $24 \mathrm{~h}$ when added alone and a reduction of approximately $2.7 \mathrm{log}$ when combined with LP and TCN. Bacterial counts remained at significantly lower levels than the control during storage, and the TCN-supplemented milk exhibited an approximately 6-log difference from the control by d 7 . In raw milk, the total bacterial growth curve showed a longer lag phase when the LS was activated by LO $(11.3 \pm 1.4$ h) compared with the control $(4.0 \pm 1.0 \mathrm{~h})$, but it was not different from the recommended method $(9.4 \pm 1.0$

Received August 10, 2018.

Accepted November 6, 2018.

${ }^{*}$ Corresponding author: alcaine@cornell.edu h). However, the total bacterial count after $24 \mathrm{~h}$ for the sample treated with LO and TCN (5.3 log cfu/mL) was significantly lower compared with the control (7.2 log $\mathrm{cfu} / \mathrm{mL}$ ) and the recommended method (6.1 log cfu/ $\mathrm{mL}$ ). Results from this study suggest that LO is an alternative source of $\mathrm{H}_{2} \mathrm{O}_{2}$ that enhances the microbial inhibition achieved by the LS. Lactose oxidase could be used to develop enzyme-based preservation technologies for applications where cold chain access is limited. This enzymatic approach to improving the shelf life of dairy products also represents a novel option for clean label spoilage control.

Key words: antimicrobial, enzymatic preservation, lactose oxidase, milk spoilage

\section{INTRODUCTION}

The activation of the lactoperoxidase system (LS), an antimicrobial system endemic to milk, is an enzymatic preservation method for inhibiting microbial growth and extending raw milk shelf life (Seifu et al., 2005). The use of this antimicrobial system is especially important in developing countries and rural areas, where refrigeration of raw milk before pasteurization is not feasible due to high costs, lack of electricity, or difficulties with maintenance and repair of equipment (Seifu et al., 2005). The LS enables moderately extended milk storage at ambient temperatures and has shown to be more profitable than cooling for small-scale dairy producers, and thereby improves their milk marketability, income, and employment opportunities (FAO/WHO, 2006).

The LS consists of 3 components: lactoperoxidase $(\mathbf{L P})$, thiocyanate $(\mathbf{T C N})$, and hydrogen peroxide $\left(\mathrm{H}_{2} \mathrm{O}_{2}\right)$. The LP enzyme catalyzes the peroxidation of TCN into hypothiocyanite ion (OTCN), which is the main antimicrobial component (De Wit and Van Hooydonk, 1996). The concentration of both TCN and $\mathrm{H}_{2} \mathrm{O}_{2}$ in the milk affects the magnitude of the antimicrobial effect. The LS has shown bacteriostatic effects against gram-positive bacteria such as streptococci and lactobacilli as well as a bactericidal effect against gram- 
negative bacteria such as pseudomonads and coliforms (Kussendrager and van Hooijdonk, 2000).

Lactoperoxidase is a heat-sensitive enzyme; its residual activity after HTST pasteurization $\left(72^{\circ} \mathrm{C}\right.$ for $15 \mathrm{~s}$ ) is approximately $70 \%$, and UHT pasteurization $\left(80^{\circ} \mathrm{C}\right.$ for $\left.15 \mathrm{~s}\right)$ inactivates it completely (Barrett et al., 1999). The average concentration of LP in raw milk is $30 \mathrm{mg} / \mathrm{L}$, whereas TCN varies between 1 and 15 $\mathrm{mg} / \mathrm{L}$ depending on factors such as animal feed and breed of cow (Kussendrager and van Hooijdonk, 2000). The natural concentration of $\mathrm{H}_{2} \mathrm{O}_{2}$ in milk, however, is not sufficient to activate the LS, and other methods are required to generate this substrate, which include (1) addition of sodium carbonate peroxyhydrate, (2) activation of $\mathrm{H}_{2} \mathrm{O}_{2}$-producing systems such as glucoseglucose oxidase and xanthine-xanthine oxidase, and (3) endogenous production of $\mathrm{H}_{2} \mathrm{O}_{2}$ by catalase-negative microorganisms (Adolphe et al., 2006; FAO/WHO, 2006).

Lactose oxidase (LO) oxidizes lactose to lactobionic acid with the concurrent reduction of $\mathrm{O}_{2}$ to $\mathrm{H}_{2} \mathrm{O}_{2}$ (Nordkvist et al., 2007). Ahmad et al. (2004) concluded that it is safe to use LO in food for human consumption. Currently, LO is primarily used for the production of lactobionic acid, a compound used by the medical industry for preservation of tissues due to its metalchelating properties. Lactobionic acid also can potentially be used in the food industry as a metal chelator, a protein and fat replacer in cheese, and a flavor enhancer (Ahmad et al., 2004). Its application as an activator of the LS or as an antimicrobial agent in dairy products has not been studied.

Pseudomonas spp. are common spoilage microorganisms associated with raw milk (De Jonghe et al., 2011) as well as postpasteurization contaminants in fluid milk (Martin et al., 2014). Stellato et al. (2017) found that P. fragi and Pseudomonas fluorescens are the most abundant species in cheese samples and processing plants. The ubiquity of Pseudomonas spp. across the dairy supply chain represents a particular challenge because the species grows well under both refrigerated and nonrefrigerated conditions, and many strains produce enzymes that reduce milk quality (Teh et al., 2011). The first part of this study explored the effects of the concentration of $\mathrm{LO}$, alone and as an activator of the LS, and of TCN on the growth of $P$. fragi in milk during storage at 6 and $21^{\circ} \mathrm{C}$. The generated data were then used as a reference to select the concentration of LO to use in 2 applications: (1) as an antimicrobial in pasteurized milk spiked with $P$. fragi and (2) as an activator of the LS in raw milk in comparison with the activation method described by FAO/WHO (1991). The results of this study describe the application of LO as a novel source of $\mathrm{H}_{2} \mathrm{O}_{2}$ that utilizes naturally present constituents of milk, lactose, and oxygen to enhance microbial inhibition achieved by the LS. Lactose oxidase could be used to create enzyme-based preservation technologies to improve the shelf life of dairy products or for applications in which refrigerated distribution is inadequate or nonexistent.

\section{MATERIALS AND METHODS}

\section{Inoculum Preparation}

A frozen stock of $P$. fragi isolated from pasteurized milk was obtained from the Cornell University Food Safety Laboratory isolate collection. The frozen culture was streaked onto brain heart infusion agar (BD Diagnostics, Franklin Lakes, NJ) and incubated at $32 \pm$ $1^{\circ} \mathrm{C}$ for $24 \mathrm{~h}$. An individual colony was then used to inoculate $5 \mathrm{~mL}$ of brain heart infusion broth, followed by $18 \mathrm{~h}$ of incubation at $32 \pm 1^{\circ} \mathrm{C}$. A $1-\mathrm{mL}$ aliquot of the overnight culture was transferred to a $1.5-\mathrm{mL}$ Eppendorf tube and centrifuged for $1 \mathrm{~min}$ at $14,000 \times g$ at 20 to $25^{\circ} \mathrm{C}$. The supernatant was removed and the cell pellet was resuspended in $1 \mathrm{~mL}$ of PBS solution (Weber Scientific, Trenton, NJ) and then used as the inoculum.

\section{Evaluation of the Concentration of LO}

One liter of UHT skim milk (Parmalat USA Corp., Grand Rapids, MI) was inoculated with P. fragi to obtain an approximate microbial load of $4 \log \mathrm{cfu} / \mathrm{mL}$. The initial bacterial concentration was confirmed by plating the inoculated milk immediately after inoculation. Bovine LP (Sigma-Aldrich, St. Louis, MO) and sodium thiocyanate (NaTCN; VWR International, Solon, $\mathrm{OH}$ ) were added to $330 \mathrm{~mL}$ of inoculated milk to a final concentration of 30 and $14 \mathrm{mg} / \mathrm{L}$, respectively. The NaTCN was prepared as a $4.6 \%$ (wt/vol) solution in distilled water and filter sterilized through a 0.20 $\mu \mathrm{m}$ pore, surfactant-free cellulose acetate filter (Corning Inc., Corning, NY). An enzymatic solution of LO (LactoYield, Chr. Hansen, Milwaukee, WI) was then added at concentrations of $0.012,0.12$, and $1.2 \mathrm{~g} / \mathrm{L}$ to individual $70-\mathrm{mL}$ aliquots of both the inoculated milk and the NaTCN-supplemented milk to obtain a total of 6 treatments (Figure 1a). Samples were aliquoted into separate test tubes for each time point and then incubated at $6 \pm 1$ or $21 \pm 1^{\circ} \mathrm{C}$, with plating for microbiological load after 1, 2, 4, and $7 \mathrm{~d}$ of storage. The experiment was carried out in triplicate, and inoculated milk with no LS-NaTCN supplementation or added enzyme was used as the control. 


\section{Evaluation of the Concentration of TCN}

One liter of UHT skim milk (Parmalat USA Corp.) was inoculated with $P$. fragi to obtain an approximate microbial load of $4 \log \mathrm{cfu} / \mathrm{mL}$. The initial bacterial concentration was confirmed by plating the inoculated milk immediately after inoculation. Bovine LP (SigmaAldrich) was added to $330 \mathrm{~mL}$ of the inoculated milk to a final concentration of $30 \mathrm{mg} / \mathrm{L}$. The NaTCN was then added to individual $70-\mathrm{mL}$ aliquots of both milk fractions to reach final concentrations of 14,140 , and $1,400 \mathrm{mg} / \mathrm{L}$, followed by the addition of LO solution (Chr. Hansen) at $0.12 \mathrm{~g} / \mathrm{L}$ to all milk samples to obtain a total of 6 treatments (Figure 1b). The NaTCN was prepared as a $32.7 \%(\mathrm{wt} / \mathrm{vol})$ solution in distilled water and filter sterilized through a $0.20-\mu \mathrm{m}$ pore, surfactantfree cellulose acetate filter. Samples were aliquoted into separate test tubes and then incubated at $6 \pm 1$ or 21 $\pm 1^{\circ} \mathrm{C}$, with plating for microbiological load after 1,2 , 4 , and $7 \mathrm{~d}$ of storage. The experiment was carried out in triplicate, and inoculated milk with no LS-NaTCN supplementation or added enzyme was used as the control.

\section{Application of LO in Pasteurized Milk}

One liter of pasteurized skim milk (Cornell University Dairy, Ithaca, NY) was inoculated with $P$. fragi to obtain an approximate load of $4 \log \mathrm{cfu} / \mathrm{mL}$. Lactose oxidase (Chr. Hansen) was incorporated into individual $70-\mathrm{mL}$ samples at concentrations of $0.006,0.012$, and $0.12 \mathrm{~g} / \mathrm{L}$. An NaTCN solution was added to $300 \mathrm{~mL}$ of inoculated milk to a concentration of $14 \mathrm{mg} / \mathrm{L}$, and afterward, LO was added to three $70-\mathrm{mL}$ samples at the same 3 concentrations previously mentioned (Figure 1c). The NaTCN was prepared as a $4.6 \%$ (wt/vol) solution in distilled water and filter sterilized through a $0.20-\mu \mathrm{m}$ pore, surfactant-free cellulose acetate filter. Samples were aliquoted into separate test tubes that were then incubated at $6 \pm 1^{\circ} \mathrm{C}$. Samples were plated for microbiological load after $0,1,2,4$, and $7 \mathrm{~d}$ of storage. The $\mathrm{pH}$ was measured for all samples at the same time
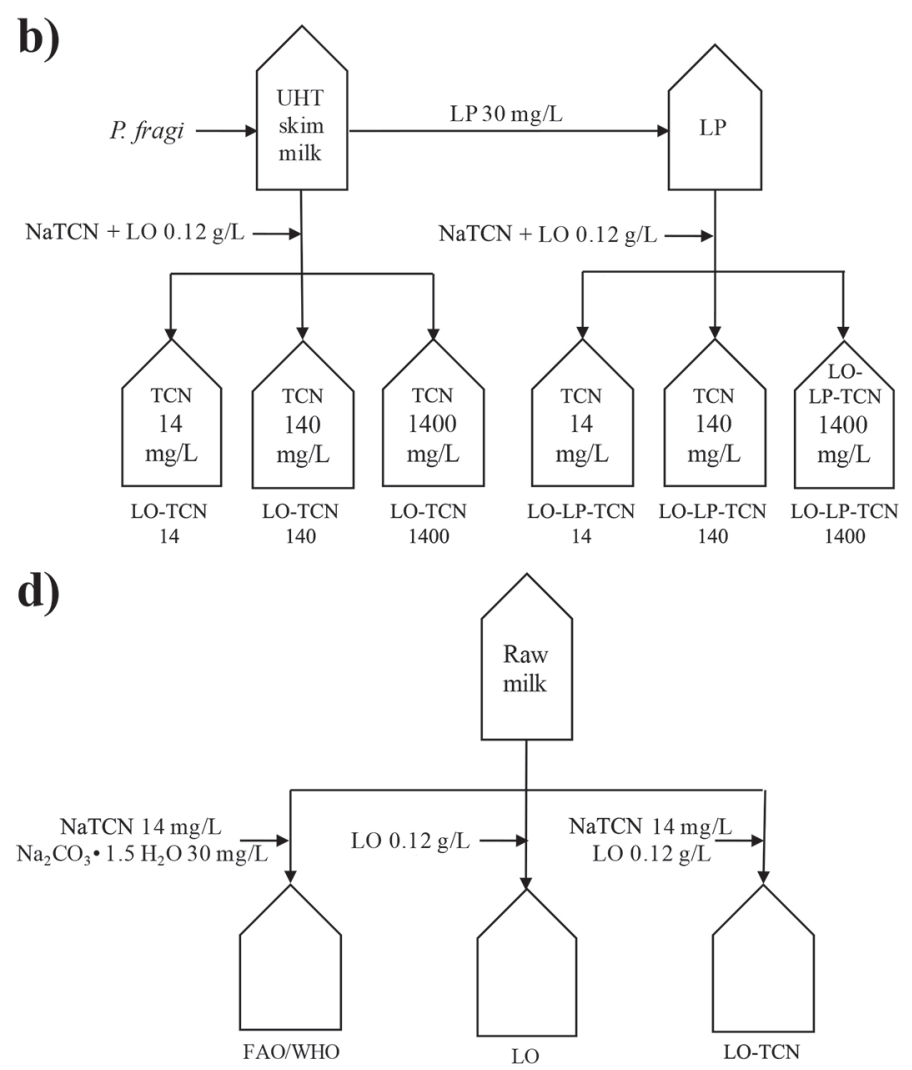

Figure 1. Schematic of sample preparations (LO = lactose oxidase; LP = lactoperoxidase; TCN = thiocyanate). (a) Numbers on the bottom label indicate the concentration of LO solution $(\mathrm{g} / \mathrm{L})$, and the labels align with Figure 2. (b) Numbers on the bottom treatment label indicate the concentration of sodium thiocyanate (NaTCN; mg/L), and the labels align with Figure 3. (c) Numbers on the bottom treatment label indicate the concentration of $\mathrm{LO}$ solution $(\mathrm{g} / \mathrm{L})$, and the labels align with Figure 4. (d) The bottom treatment labels align with Figure 5. FAO/ WHO (1991). P. fragi = Pseudomonas fragi. 
points. The experiment was carried out in triplicate, and inoculated milk with no LS-NaTCN supplementation or added enzyme was used as the control.

\section{Application of LO as Raw Milk Preservative}

Whole raw milk was collected from the teaching barn at Cornell University within $1 \mathrm{~h}$ from the time of milking. The bottle containing the milk was inverted 25 times before dividing it into 3 separate 1-L samples (Figure 1d). The first milk sample was prepared following the process described by FAO/WHO (1991), which consists of the addition of $14 \mathrm{mg} / \mathrm{L}$ of NaTCN and 30 $\mathrm{mg} / \mathrm{L}$ of sodium percarbonate. The solution of NaTCN $(0.028 \mathrm{~g} / \mathrm{mL})$ was prepared in distilled water and filter sterilized through a $0.20-\mu \mathrm{m}$ pore surfactant-free cellulose acetate filter. The solution of sodium percarbonate $(0.06 \mathrm{~g} / \mathrm{mL})$ was made in sterilized distilled-deionized water and was immediately added after preparation. The second milk sample was prepared by adding NaTCN and LO (Chr. Hansen) solutions to reach final concentrations of $14 \mathrm{mg} / \mathrm{L}$ and $0.12 \mathrm{~g} / \mathrm{L}$, respectively. The third milk sample was prepared by adding the LO solution to reach a concentration of $0.12 \mathrm{~g} / \mathrm{L}$. All samples were incubated at $21 \pm 1^{\circ} \mathrm{C}$ for $24 \mathrm{~h}$, and a total microbial count was carried out every $2 \mathrm{~h}$ for the first $12 \mathrm{~h}$ of incubation and every $4 \mathrm{~h}$ for the remaining time. The $\mathrm{pH}$ was measured for all samples at the same time points. The experiment was carried out in triplicate, and inoculated milk with no supplementation or added enzyme was used as the control.

\section{Microbiological Analysis}

Before plating, serial dilutions of each milk sample to be analyzed were prepared in phosphate buffer and each dilution was spread plated in duplicate on SPC agar. Plates were incubated at $32 \pm 1^{\circ} \mathrm{C}$ for $48 \mathrm{~h}$ before enumeration.

\section{Statistical Analysis}

All statistical analyses were performed using $\mathrm{R}$ (version 3.4.1; R Development Core Team, Vienna, Austria). Analysis of variance and Tukey's honest significant difference test were performed individually for each time point to compare the log differences in microbial counts between treatments corresponding to the evaluation of the concentration of LO and TCN as well as from the application of LO in pasteurized milk. To analyze data obtained from the application of LO in raw milk, Buchanan growth curve models with no $\log _{10}$ of final population density $\left(\mathrm{N}_{\max }\right)$ parameter were fit using the nlsMicrobio and nlstools packages in R. Using the confint2 function of nlstools, asymptotic 95\% confidence intervals were calculated for the lag phase, maximum growth rate, and initial concentration for every treatment. Estimates were regarded as significantly different if the $95 \%$ confidence intervals did not overlap. In addition, ANOVA and Tukey's honest significant difference test were performed to compare the total microbial counts between treatments after 24 h. A count from the evaluation of the concentration of TCN (14 mg/L of TCN, $0.12 \mathrm{~g} / \mathrm{L}$ of LO solution, d 7) was considered an outlier based on results from previous experiments and on 3 other independent replicates of the same treatment, and thus that count was not included in subsequent analysis.

\section{RESULTS AND DISCUSSION}

\section{Concentration of LO}

Different concentrations of an LO solution were evaluated to determine the effectiveness of inhibiting the growth of $P$. fragi in skim milk. For this study, a $P$. fragi strain isolated from pasteurized milk was selected as the indicator of microbial inhibition. The LO solution was added alone to determine whether it had an antimicrobial effect via $\mathrm{H}_{2} \mathrm{O}_{2}$ production as well as in combination with NaTCN and LP to evaluate its potential as an activator of the LS.

At $6^{\circ} \mathrm{C}$, the increase in concentration of $\mathrm{LO}$ caused higher reductions of $P$. fragi during $7 \mathrm{~d}$ of storage compared with the control (Figure 2a). When LO solution was added at $0.012 \mathrm{~g} / \mathrm{L}$, P. fragi counts were generally lower than the control for the first $48 \mathrm{~h}$ of storage. However, by $\mathrm{d} 4$ and 7 , the bacterial counts for both LO and LP-TCN-LO treatments were no different than the control. At the lowest LO concentration, no significant difference was shown between the addition of LO alone or LO combined with LS components at the end of the study. Samples treated with $0.12 \mathrm{~g} / \mathrm{L}$ of LO showed an initial reduction of $P$. fragi of approximately $2.5 \mathrm{log}$ within $24 \mathrm{~h}$ followed by a slight increase of less than $1 \log$ by $\mathrm{d} 7$. The counts for this treatment were consistently lower than the control. The same bactericidal effect within $24 \mathrm{~h}$ was achieved when LO was used at $0.12 \mathrm{~g} / \mathrm{L}$ in the presence of LP and NaTCN. In addition, this treatment had a bacteriostatic effect on $P$. fragi during the remaining days of storage, and counts were significantly lower compared with LO alone on d 4 and 7. A reduction of $P$. fragi below the detection limit was achieved in $24 \mathrm{~h}$ when LO was added at 1.2 $\mathrm{g} / \mathrm{L}$, and no regrowth occurred after $7 \mathrm{~d}$ of storage. Due to bacterial counts being below the limit of detection 

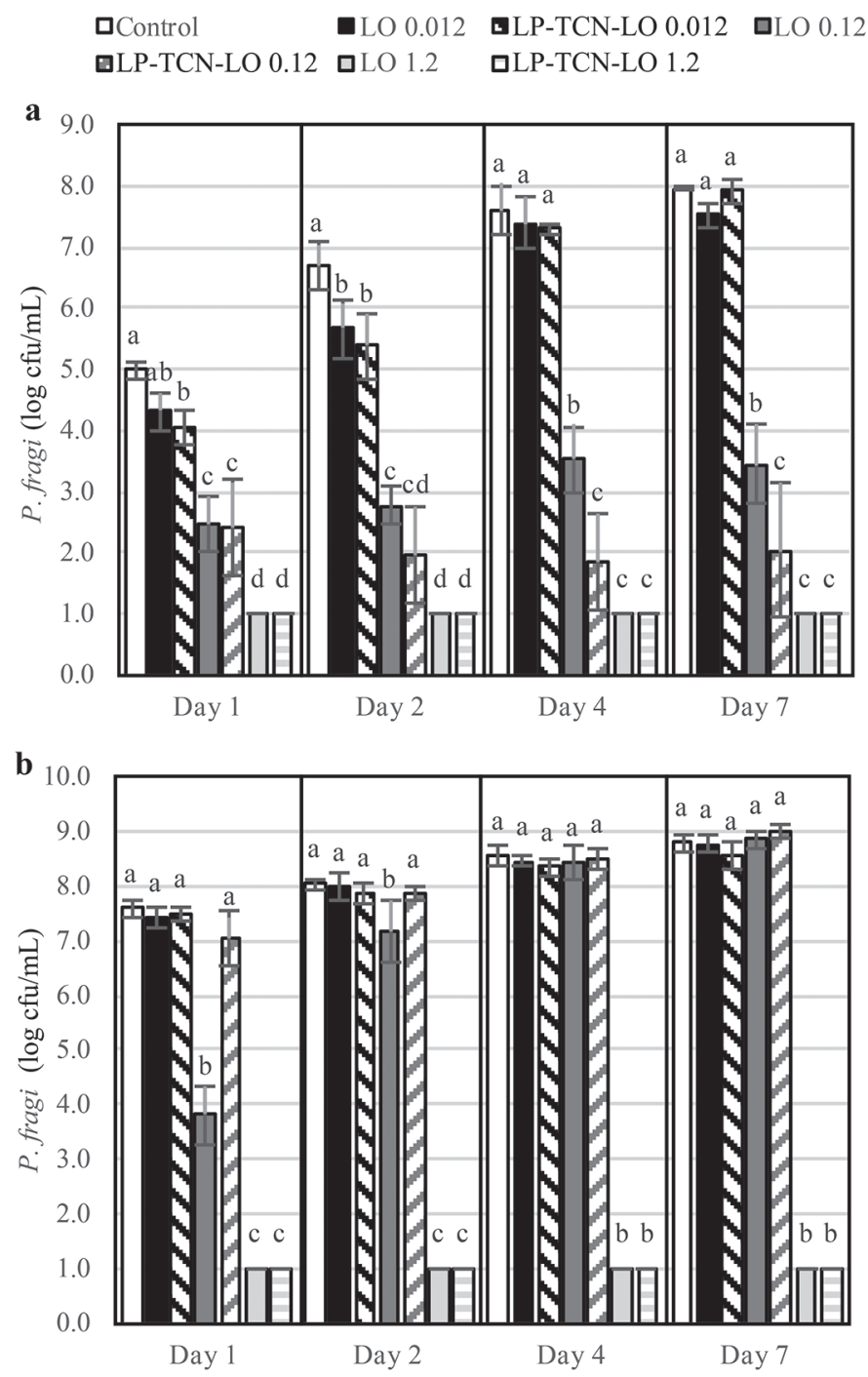

Figure 2. Pseudomonas fragi counts in skim milk treated with lactose oxidase (LO) and the lactoperoxidase system during storage at (a) $6^{\circ} \mathrm{C}$ and (b) $21^{\circ} \mathrm{C} . \mathrm{LP}=$ lactoperoxidase; $\mathrm{TCN}=$ thiocyanate. Numbers on the treatment label indicate the concentration of LO solution $(\mathrm{g} / \mathrm{L})$. Bars with different letters $(\mathrm{a}-\mathrm{d})$ indicate significant difference $(P<0.001)$ between treatments on the same day. For counts lower than the limit of detection, a value of $1 \log _{10} \mathrm{cfu} / \mathrm{mL}$ was used for the statistical analysis. Error bars represent the SD.

at this concentration, no difference could be observed between the antimicrobial effect of $\mathrm{LO}$ added alone or combined with the LS components. Results suggest that at $1.2 \mathrm{~g} / \mathrm{L}$ concentration of $\mathrm{LO}$, the production of $\mathrm{H}_{2} \mathrm{O}_{2}$ was sufficient to kill $P$. fragi below the detection limit regardless of the presence of the LS.

None of the systems containing LO solution at 0.012 $\mathrm{g} / \mathrm{L}$ had an inhibitory effect on the growth of $P$. fragi at $21^{\circ} \mathrm{C}$. At a concentration of $0.12 \mathrm{~g} / \mathrm{L}, \mathrm{LO}$ alone showed a bacteriostatic effect for $24 \mathrm{~h}$ followed by regrowth to a concentration not significantly different from the con- trol or its LS counterpart. As observed for treatments at $6^{\circ} \mathrm{C}$, at a concentration of $1.2 \mathrm{~g} / \mathrm{L}, \mathrm{LO}$ exhibited bactericidal activity and $P$. fragi was reduced to undetectable concentrations within $24 \mathrm{~h}$, with no regrowth after $7 \mathrm{~d}$.

The greater antimicrobial activity with higher LO concentration could be caused by increased production of $\mathrm{H}_{2} \mathrm{O}_{2}$. This compound acts as an antimicrobial and as a substrate of the LS that promotes oxidation of TCN to OTCN. Martin et al. (2014) reported that the higher the concentration of $\mathrm{H}_{2} \mathrm{O}_{2}$ in raw milk, the greater the antimicrobial effect on total bacterial count over time during storage at 6 and $21^{\circ} \mathrm{C}$. Similarly, Listeria monocytogenes growth was inhibited in raw milk during 21 $\mathrm{d}$ at a concentration of $100 \mathrm{mg} / \mathrm{L}$ of $\mathrm{H}_{2} \mathrm{O}_{2}$, whereas at concentrations of 400 and $800 \mathrm{mg} / \mathrm{L}$ counts were reduced to undetectable levels within 24 h (Kozak et al., 2018). Other studies have reported bacterial inhibition due to the production of $\mathrm{H}_{2} \mathrm{O}_{2}$ by enzymatic systems such as glucose oxidase-glucose in milk (Dionysius et al., 1992) and liquid whole egg (Dobbenie et al., 1995).

Gram-negative microorganisms such as pseudomonads can be both inhibited by compounds produced by the LS and killed by $\mathrm{H}_{2} \mathrm{O}_{2}$ (De Wit and Van Hooydonk, 1996), which may explain the enhanced antimicrobial effect observed when LO was added in the presence of TCN and LP. Reiter et al. (1976) studied the activation of the LS using glucose oxidase and reported that the bactericidal effect occurred in 2 stages, the first due to TCN oxidation by LP and the second due to the accumulation of $\mathrm{H}_{2} \mathrm{O}_{2}$. This combined effect is consistent with a previous study that showed greater antimicrobial activity against Staphylococcus aureus, Pseudomonas aeruginosa, and Bacillus cereus for the LS compared with $\mathrm{H}_{2} \mathrm{O}_{2}$ alone (Fweja et al., 2008). Our results also indicate that the natural concentration of lactose in milk is adequate to promote the production of $\mathrm{H}_{2} \mathrm{O}_{2}$ via $\mathrm{LO}$ and obtain the described antimicrobial effect.

All treatments were more effective at inhibiting the growth of $P$. fragi in milk at refrigeration temperature than at room temperature (Figure 2), except at a concentration of $1.2 \mathrm{~g} / \mathrm{L}$ of $\mathrm{LO}$. These results are in agreement with those reported by Martin et al. (2014), where $\mathrm{H}_{2} \mathrm{O}_{2}$ provided a higher bacterial inhibitory effect at $6^{\circ} \mathrm{C}$ than at $21^{\circ} \mathrm{C}$. Although the TCN peroxidation reaction rate is higher at room temperature than at refrigeration temperatures (Adolphe et al., 2006), it is likely that the concentration of the antimicrobial product was not sufficient to inhibit growth of $P$. fragi under conditions that promote more active bacterial growth. FAO/WHO (2006) explained that the inhibitory effect of the LS depends on the storage temperature of the milk, ranging from 5 to $6 \mathrm{~d}$ at $4^{\circ} \mathrm{C}$ and 16 to $17 \mathrm{~h}$ 
at $20^{\circ} \mathrm{C}$. Results from this study were consistent with those observations.

\section{Concentration of TCN}

The principal antimicrobial compound produced by the LS is hypothiocyanite (OTCN) and it is the result of the peroxidase-catalyzed oxidation of TCN. This compound, known as a hypopseudohalide, is a potent oxidant with antimicrobial activity (Bafort et al., 2014); OTCN oxidizes the sulfhydryl groups of proteins to disulfides, causing structural damage of microbial cytoplasmatic membranes (Kussendrager and van Hooijdonk, 2000). The antimicrobial activity of the LS is affected by concentration of TCN and by the method used to generate $\mathrm{H}_{2} \mathrm{O}_{2}$, as they both affect the concentration of OTCN and LP activity (Dionysius et al., 1992).

Based on observations from preliminary studies, we hypothesized that the level of TCN affects activity of the LS and might influence the activity of LO. Various TCN concentrations were evaluated to study its effect on the antimicrobial activity of $\mathrm{LO}$ alone and combined with LP. All treatments had a bactericidal effect at $6^{\circ} \mathrm{C}$ during the first $48 \mathrm{~h}$, and, in general, there was no significant difference between samples treated with LO only or with the LS. The LO-treated samples exhibited bactericidal effect over time with counts approximately $7 \log$ lower than the control by d 7. At NaTCN concentrations of 140 and $1,400 \mathrm{mg} / \mathrm{L}$, P. fragi was reduced below the detection limit after $4 \mathrm{~d}$. Similarly, activation of the LS with $14 \mathrm{mg} / \mathrm{L}$ of NaTCN showed bactericidal activity during $7 \mathrm{~d}$ of storage, and counts were not significantly different when compared with the LO treatments. In contrast, LS treatments at 140 and 1,400 $\mathrm{mg} / \mathrm{L}$ of NaTCN exhibited regrowth on d 7. Counts for these 2 treatments were significantly lower than the control at every time point; however, they were significantly less effective at inhibiting growth of $P$. fragi than LO alone or the LS activated with $14 \mathrm{mg} / \mathrm{L}$ of NaTCN.

At $21^{\circ} \mathrm{C}$, the higher the concentration of TCN led to greater antimicrobial effect of the LO enzyme over storage time. The combination of TCN at $14 \mathrm{mg} / \mathrm{L}$ and LO exhibited a bacteriostatic effect for $24 \mathrm{~h}$ followed by regrowth of $P$. fragi to concentrations not significantly different from the control. However, LO combined with 140 and 1,400 mg/L of NaTCN showed bactericidal activity. In the first case, P. fragi was gradually reduced over time until reaching a concentration below the detection limit on $\mathrm{d} 7$. In the latter case, $P$. fragi levels were reduced below detection limits within $24 \mathrm{~h}$ and no regrowth was detected after $7 \mathrm{~d}$. In contrast, the concentration of TCN did not have a significant effect on the antimicrobial activity of the LS at room temperature. The inhibition of $P$. fragi did not increase significantly with the addition of higher levels of TCN except on $\mathrm{d} 7$ at the highest concentration; however, outgrowth was not inhibited.

Interestingly, results shown in Figure 3 showed reduced inactivation of $P$. fragi at both temperatures when LP was present compared with systems with LO and TCN alone, particularly at increased levels of TCN. One explanation for the reduced antimicrobial activity of the LS at the 2 higher levels of NaTCN evaluated in this study is that LP function can be inhibited by an excess level of TCN. The anion can bind to the native enzyme, restricting the binding site to $\mathrm{H}_{2} \mathrm{O}_{2}$ and altering the subsequent reactions that lead to the production of antimicrobial compounds by the LS (Bafort et al., 2014). Dionysius et al. (1992), however, reported that increasing the concentration of TCN caused only a slight increase in production of the oxidation product and suggested that production of $\mathrm{H}_{2} \mathrm{O}_{2}$ was the ratelimiting factor in the enzymatic reaction. In all treatments, LO produced $\mathrm{H}_{2} \mathrm{O}_{2}$, which acts as the primary antimicrobial agent under LP-free conditions. If in the conditions containing LP and LO the higher levels of TCN inhibited LP activity, the nonutilized $\mathrm{H}_{2} \mathrm{O}_{2}$ would be free to act as an antimicrobial compound as in the LP-free condition, and one might expect to see similar levels of inhibition, but this was not observed. These results suggest an interaction or potential synergistic effect between LO and TCN that improved the inactivation of $P$. fragi in the absence of LP. To control for the effect of TCN on P. fragi counts, milk samples were exposed to all 3 concentrations of NaTCN. Counts for NaTCN controls were not significantly different from the control (data not shown), which means that NaTCN had no antimicrobial activity individually and reinforces the theory of a synergistic effect with LO. The influence of TCN on LO activity has not been studied, and future research is needed to understand this potentially new mechanism of inhibition.

These results suggest that addition of both LO and TCN could be studied as a potential antimicrobial system in other food matrices. Data from this study showed that both temperature and TCN concentration affect the extent of bacterial reduction achieved by the LO-TCN system. When considering the addition of TCN, some studies suggest that high levels of TCN can interfere with iodine metabolism and reduce its uptake by the thyroid gland (FAO/WHO, 2006); however, the effect is adverse only in individuals with iodine deficiency (Laurberg et al., 2009). In addition, a concentration of NaTCN of approximately $20 \mathrm{mg} / \mathrm{L}$, which proved to be effective in this study, is 10 to 20 times lower than the level that was shown to have an effect on iodine metabolism (FAO/WHO, 2006). 


\section{Application of LO in Pasteurized Milk}

Pseudomonas spp. is the most common bacteria associated with postpasteurization contamination of fluid milk, a problem that affects approximately $50 \%$ of the supply (Martin et al., 2018). Pasteurized skim milk was spiked with $P$. fragi and then treated with LO alone or combined with NaTCN to evaluate the interaction with the native LS that remains active after HTST pasteurization. A maximum concentration of $0.12 \mathrm{~g} / \mathrm{L}$ of LO solution was selected based on previous results (Figure 2a) and considering the potential effect of the enzyme concentration on sensory attributes and cost.

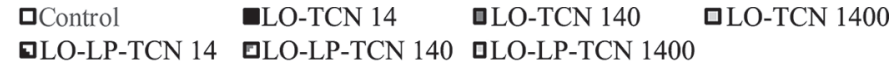

a
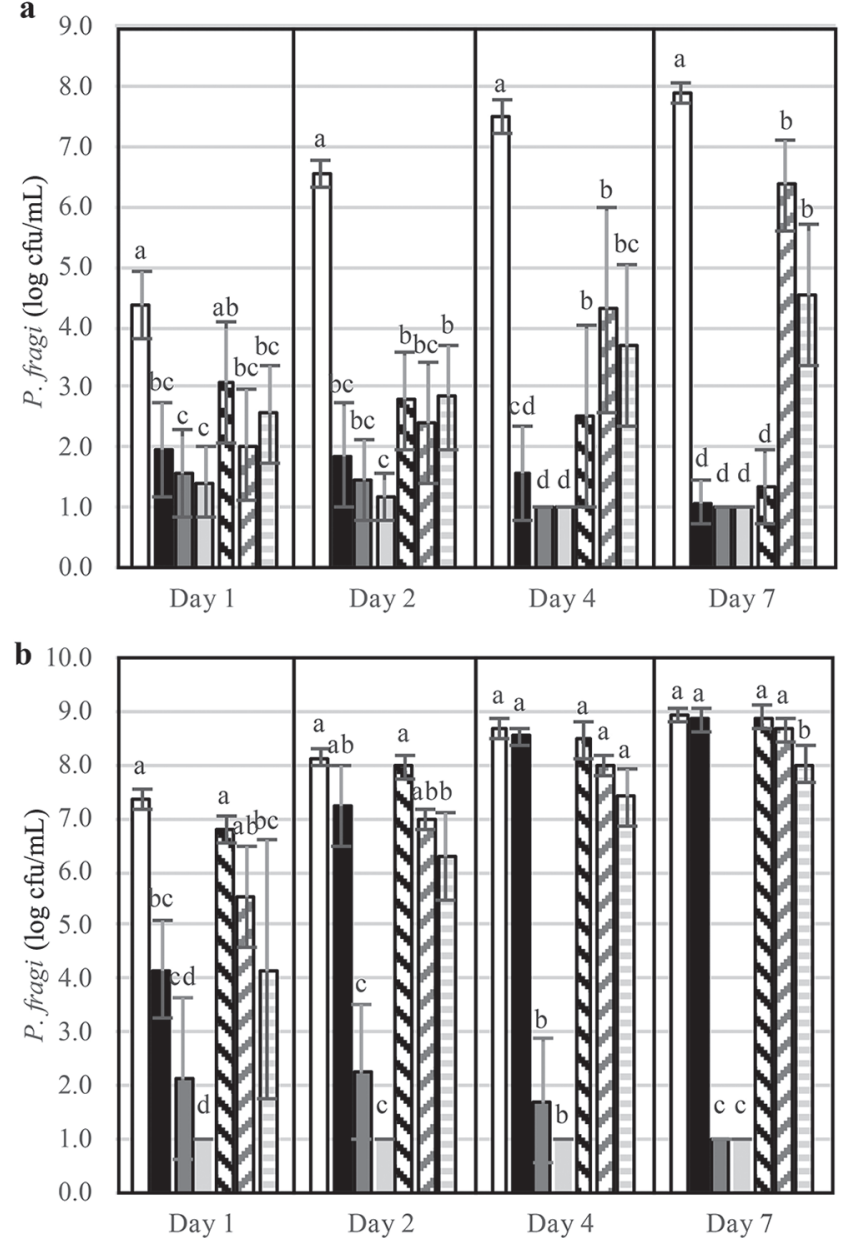

Figure 3. Pseudomonas fragi counts in skim milk treated with lactose oxidase (LO) and the lactoperoxidase system at different concentrations of sodium thiocyanate $(\mathrm{NaTCN})$ during storage at (a) $6^{\circ} \mathrm{C}$ and $(\mathrm{b}) 21^{\circ} \mathrm{C} . \mathrm{LP}=$ lactoperoxidase; $\mathrm{TCN}=$ thiocyanate. Numbers on the treatment label indicate the concentration of NaTCN $(\mathrm{mg} / \mathrm{L})$. Bars with different letters $(\mathrm{a}-\mathrm{d})$ indicate significant difference $(P<$ 0.001 ) between treatments on the same day. For counts lower than the limit of detection, a value of $1 \log _{10} \mathrm{cfu} / \mathrm{mL}$ was used for the statistical analysis. Error bars represent the SD.
Lower concentrations were also tested to determine whether there was an antimicrobial effect when applied in a commercial sample compared with the model systems. The NaTCN was added at $14 \mathrm{mg} / \mathrm{L}$ based on results shown in Figure 3a and usage recommendations by FAO/WHO (1991).

Figure 4 shows that concentrations of 0.006 and 0.012 $\mathrm{g} / \mathrm{L}$ of LO solution caused no significant effect on $P$. fragi counts compared with the control, and no significant difference was observed between adding LO with or without NaTCN supplementation. This contrasts with results shown in Figure 2a, where the addition of $\mathrm{LO}$ at a concentration of $0.012 \mathrm{~g} / \mathrm{L}$ showed antimicrobial activity during $48 \mathrm{~h}$ regardless of the concentration of NaTCN. Results suggest that production of $\mathrm{H}_{2} \mathrm{O}_{2}$ at these concentrations was not sufficiently high enough to activate the LS or act as an antimicrobial. The discrepancy between results could be due to a difference between the activity of LP present in the model systems and in the pasteurized milk. High temperature, short time pasteurization reduces LP activity up to $30 \%$ (De Wit and Van Hooydonk, 1996; Barrett et al., 1999), which has a direct effect on its antimicrobial power.

The LO solution added at $0.12 \mathrm{~g} / \mathrm{L}$ reduced $P$. fragi counts within the first $24 \mathrm{~h}$ at both levels of NaTCN. The LO-treated milk showed an initial reduction of approximately $1.4 \mathrm{log}$, and counts remained relatively

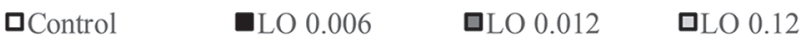 口TCN-LO 0.006 口TCN-LO 0.012 aTCN-LO 0.12}

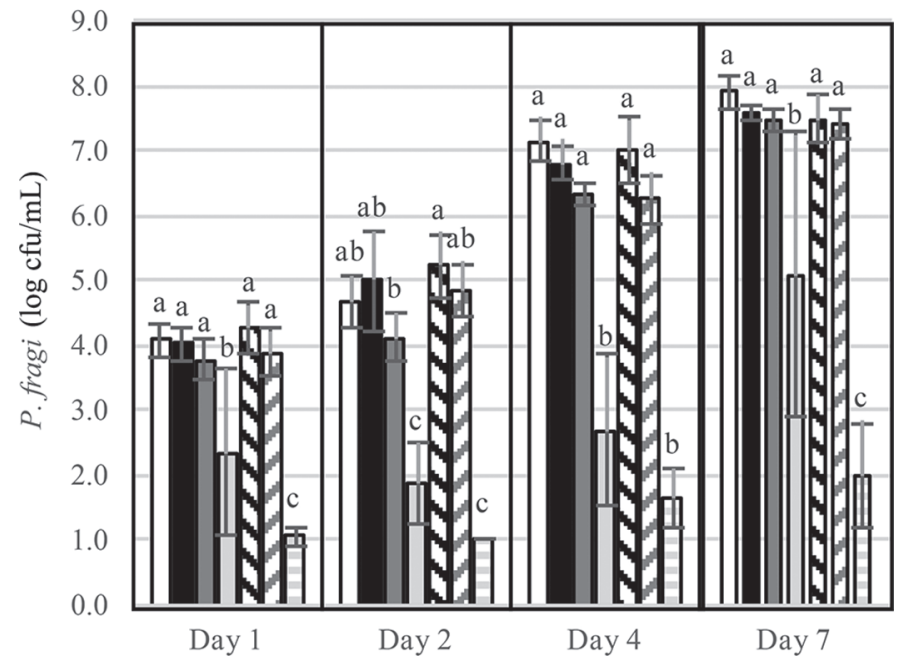

Figure 4. Pseudomonas fragi counts in pasteurized milk treated with lactose oxidase (LO) and the lactoperoxidase system during storage at $6^{\circ} \mathrm{C}$. TCN $=$ thiocyanate. Numbers on the treatment label indicate the concentration of LO solution $(\mathrm{g} / \mathrm{L})$. Bars with different letters $(\mathrm{a}-\mathrm{c})$ indicate significant difference $(P<0.001)$ between treatments on the same day. For counts lower than the limit of detection, a value of $1 \log _{10} \mathrm{cfu} / \mathrm{mL}$ was used for the statistical analyses. Error bars represent the SD. 
constant with a difference of less than 1 log between counts over the first $4 \mathrm{~d}$. Regrowth occurred by $\mathrm{d} 7$, but $P$. fragi counts were still significantly lower compared with the control. The addition of TCN to activate the LS caused an approximately 2.7-log reduction of $P$. fragi after $24 \mathrm{~h}$. Counts increased approximately $1 \mathrm{log}$ by $\mathrm{d} 4$ and 7 but never exceeded the initial inoculum level. By d 7, the supplemented milk exhibited an approximately 6-log difference versus the control and significantly lower counts compared with the rest of the treatments. Supplementation with NaTCN enhanced the antimicrobial effect of the LS and helped in maintaining $P$. fragi at low levels during storage compared with the LO-treated sample. This effect was expected, as $8 \mathrm{mg} / \mathrm{L}$ is the average concentration of TCN in bulk milk and $15 \mathrm{mg} / \mathrm{L}$ is the minimum required for activation of the LS (Seifu et al., 2005; FAO/WHO, 2006).

According to the results, the remaining activity of LP after pasteurization is sufficient to achieve important microbial reductions. Lactose oxidase could be added to pasteurized milk to extend shelf life or to inhibit spoilage in the case of postpasteurization contamination. In this study, the initial inoculum level was high and close to the Pasteurized Milk Ordinance SPC limit of $20,000 \mathrm{cfu} / \mathrm{mL}$. However, the initial level of postpasteurization contamination is in general very low (Schröder, 1984) and could be inhibited by a reduced concentration of LO. FAO/WHO (2006) explained that the antimicrobial effect of the LS is inversely correlated with bacterial concentration, wherein its efficacy is low at high bacterial levels, bacteriostatic at intermediate levels, and bactericidal at low levels.

The effect of adding LO on the sensory attributes of milk should be noted. The production of lactobionic acid causes a decrease in milk $\mathrm{pH}$ and could potentially change its flavor. Table 1 shows that the lowest $\mathrm{pH}$ of pasteurized milk decreased to 6.46 after $7 \mathrm{~d}$ of storage for the most effective treatment (TCN-LO at $0.12 \mathrm{~g} / \mathrm{L}$ ). However, longer storage periods or higher concentrations of enzyme might cause a more dramatic effect that affects both sensory quality and functionality of milk. Technologies such as enzyme immobilization could be explored as an option to control the contact time between the milk and enzyme to achieve the desired antimicrobial effect while controlling the production of acid.

\section{Application of LO as a Raw Milk Preservative}

The addition of LO as an activator of the LS was compared with the reference method described in the guidelines by FAO/WHO (1991) to activate the antimicrobial system in raw milk. The FAO/WHO method consists of adding $14 \mathrm{mg} / \mathrm{L}$ of NaTCN and $30 \mathrm{mg} / \mathrm{L}$ of

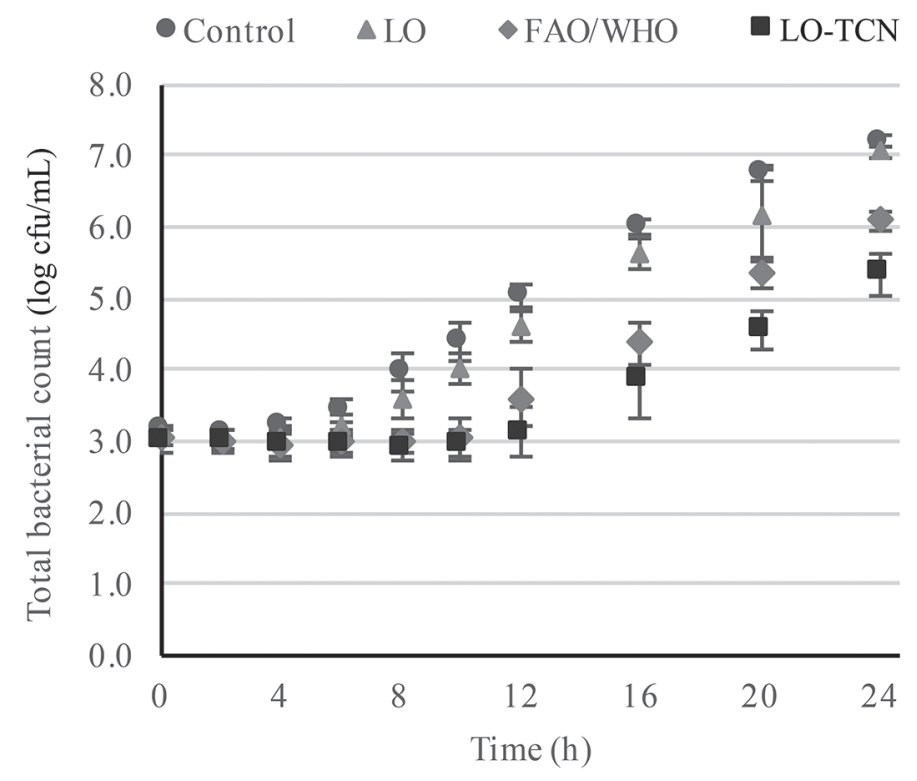

Figure 5. Total bacterial growth curve in raw milk treated by various preservation methods. $\mathrm{LO}=0.12 \mathrm{~g} / \mathrm{L}$ of lactose oxidase; FAO/ WHO $(1991)=14 \mathrm{mg} / \mathrm{L}$ of sodium thiocyanate $(\mathrm{NaTCN})$ and 30 $\mathrm{mg} / \mathrm{L}$ of sodium percarbonate; $\mathrm{LO}-\mathrm{TCN}=0.12 \mathrm{~g} / \mathrm{L}$ of lactose oxidase and $14 \mathrm{mg} / \mathrm{L}$ of NaTCN during storage at $21^{\circ} \mathrm{C}$. Error bars represent the SD.

sodium percarbonate as the source of $\mathrm{H}_{2} \mathrm{O}_{2}$. Previous results from this study were used as a reference, and $\mathrm{LO}$ was added at $0.12 \mathrm{~g} / \mathrm{L}$ both alone and in addition to $14 \mathrm{mg} / \mathrm{L}$ of NaTCN. Milk was stored at $21^{\circ} \mathrm{C}$, and total bacterial growth was monitored for $24 \mathrm{~h}$ (Figure $5)$ to compare the results with the 16- to 17-h range of microbial inhibition reported by FAO/WHO (1991, 2006) at that temperature.

The average lag phase was significantly longer for samples treated with both LO and TCN $(P<0.05)$, providing an average 7.3-h extension over the control and an average 5.9-h extension over LO alone, but it did not significantly differ from the reference method

Table 1. $\mathrm{pH}( \pm \mathrm{SD})$ of pasteurized milk treated with lactose oxidase during storage at $6^{\circ} \mathrm{C}$

\begin{tabular}{lccc}
\hline & \multicolumn{3}{c}{ Time (d) } \\
\cline { 2 - 4 } Treatment $^{1}$ & 1 & 4 & 7 \\
\hline Control & $6.73 \pm 0.02$ & $6.71 \pm 0.03$ & $6.71 \pm 0.02$ \\
LO & & & \\
$0.006 \mathrm{~g} / \mathrm{L}$ & $6.71 \pm 0.02$ & $6.67 \pm 0.01$ & $6.65 \pm 0.02$ \\
$0.012 \mathrm{~g} / \mathrm{L}$ & $6.70 \pm 0.03$ & $6.64 \pm 0.02$ & $6.60 \pm 0.02$ \\
$0.12 \mathrm{~g} / \mathrm{L}$ & $6.66 \pm 0.03$ & $6.56 \pm 0.02$ & $6.44 \pm 0.03$ \\
TCN-LO & & & \\
$0.006 \mathrm{~g} / \mathrm{L}$ & $6.71 \pm 0.03$ & $6.66 \pm 0.05$ & $6.63 \pm 0.06$ \\
$0.012 \mathrm{~g} / \mathrm{L}$ & $6.70 \pm 0.03$ & $6.65 \pm 0.03$ & $6.60 \pm 0.03$ \\
$0.12 \mathrm{~g} / \mathrm{L}$ & $6.65 \pm 0.03$ & $6.55 \pm 0.04$ & $6.46 \pm 0.04$ \\
\hline
\end{tabular}

${ }^{1} \mathrm{LO}=$ lactose oxidase $\mathrm{TCN}=$ thiocyanate $\mathrm{n}=3$. 
Table 2. Parameters $( \pm \mathrm{SD} ; \mathrm{n}=3)$ determined from the total bacterial growth curve in raw milk stored at $21^{\circ} \mathrm{C}$

\begin{tabular}{|c|c|c|c|c|}
\hline Treatment $^{1}$ & $\begin{array}{l}\text { Lag phase } \\
\text { (h) }\end{array}$ & $\begin{array}{l}\text { Maximum growth } \\
\text { rate }(\log \mathrm{cfu} / \mathrm{h})\end{array}$ & $\begin{array}{c}\text { 24-h count } \\
(\log \mathrm{cfu} / \mathrm{mL})\end{array}$ & 24-h pH \\
\hline $\begin{array}{l}\text { Control } \\
\text { FAO/WHO (1991) } \\
\text { LO } \\
\text { LO-TCN }\end{array}$ & $\begin{array}{r}4.0 \pm 1.0^{\mathrm{a}} \\
9.4 \pm 1.0^{\mathrm{b}} \\
5.4 \pm 0.9^{\mathrm{a}} \\
11.3 \pm 1.4^{\mathrm{b}}\end{array}$ & $\begin{array}{l}0.50 \pm 0.04 \\
0.49 \pm 0.05 \\
0.51 \pm 0.03 \\
0.42 \pm 0.07\end{array}$ & $\begin{array}{l}7.21 \pm 0.07^{\mathrm{C}} \\
6.09 \pm 0.12^{\mathrm{B}} \\
7.06 \pm 0.08^{\mathrm{C}} \\
5.34 \pm 0.30^{\mathrm{A}}\end{array}$ & $\begin{array}{l}6.68 \pm 0.01 \\
6.72 \pm 0.01 \\
6.66 \pm 0.01 \\
6.67 \pm 0.01\end{array}$ \\
\hline
\end{tabular}

(Table 2). The average maximum growth rate during the exponential phase was $0.48 \mathrm{log} \mathrm{cfu} / \mathrm{h}$, and no significant difference $(P>0.05)$ was found between treatments. However, the total bacterial count after $24 \mathrm{~h}$ for the sample treated with LO and TCN was significantly lower $(P<0.0001)$ compared with the other treatments, wherein the final count was approximately 1.8 log lower than the control and LO added alone and approximately $0.8 \log$ lower compared with the reference method. This is consistent with reports that mention that production of $\mathrm{H}_{2} \mathrm{O}_{2}$ by enzymatic systems such as glucose oxidase-glucose and xanthine oxidase-hypoxanthine may improve the antimicrobial activity of the LS compared with added $\mathrm{H}_{2} \mathrm{O}_{2}$ (Kussendrager and van Hooijdonk, 2000). According to Dionysius et al. (1992), the $\mathrm{H}_{2} \mathrm{O}_{2}$ :OTCN ratio is low when an enzymatic method is used to generate $\mathrm{H}_{2} \mathrm{O}_{2}$, and that promotes OTCN as the main oxidation product. When the ratio is high, excess $\mathrm{H}_{2} \mathrm{O}_{2}$ oxidizes OTCN, leading to the formation of other compounds with no antimicrobial activity. This could explain the enhanced antimicrobial activity achieved when the LO-lactose system was used as the activation method. It should be noted that LO activated the LS and that microbial growth was inhibited regardless of the higher fat content of this sample, in contrast with skim milk samples used in previous experiments.

Consistent with previously discussed results, supplementation with NaTCN improved the antimicrobial effect of the LS. It is likely that the concentration of TCN in the milk was insufficient to activate the LS, and therefore the addition of LO alone showed no significant difference in the evaluated parameters compared with the control. Overall, the LS activation method of adding LO and TCN showed the most potential for preservation of raw milk stored under nonrefrigerated conditions, and its inhibition effect is comparable with the reference method.

An advantage of the application of LO as an activator of the LS is that lactose, its substrate, is naturally pres- ent in milk. On the contrary, the use of other enzymatic systems might imply the addition of exogenous sugars such as glucose. Another promising result is that, as shown in Table 2, after $24 \mathrm{~h}$ the $\mathrm{pH}$ for the sample treated with LO and NaTCN was still approximately 6.7, which is the normal value for fresh milk (Walstra et al., 2005). Because the activation of the LS is not a substitute for pasteurization (FAO/WHO, 1991), subsequent heat treatment of the raw milk would cause inactivation of $\mathrm{LO}$, which has been shown to be inactivated at $60^{\circ} \mathrm{C}$ for $30 \mathrm{~min}$ (Ahmad et al., 2004), and thus stop further acid production.

\section{CONCLUSIONS}

Results from this study suggest that LO can act as an alternative propagation source of $\mathrm{H}_{2} \mathrm{O}_{2}$, which enhances the microbial inhibition achieved by the LS, and may work synergistically with TCN in the absence of LP. Lactose oxidase could be used to create enzyme-based preservation technologies for applications in locations where cold chain access is limited. Additionally, LO proved to be effective under refrigeration conditions, showing that it could be used as a preservative in situations where raw milk needs to be held for extended periods of time before pasteurization and further processing. Additional studies should address methods such as enzyme immobilization to prevent $\mathrm{pH}$ decrease in the milk for applications of LO in final products such as pasteurized milk. Finally, because enzymes are present in diverse dairy foods, the application of LO as an antimicrobial represents an opportunity for the dairy industry to benefit from an extended shelf life of their products while meeting the consumer desire for clean ingredient labels.

\section{ACKNOWLEDGMENTS}

The authors thank the New York State Milk Promotion Advisory Board (Albany, NY), via the New York 
State Department of Agriculture and Markets, for their support of this research. The authors also thank the staff and students of the Food Safety Laboratory (Cornell University, Ithaca, NY) for their assistance with this study.

\section{REFERENCES}

Adolphe, Y., M. Jacquot, M. Linder, A. M. Revol-Junelles, and J. B. Milliere. 2006. Optimization of the components concentrations of the lactoperoxidase system by RSM. J. Appl. Microbiol. 100:10341042.

Ahmad, S. K., D. S. Brinch, E. P. Friis, and P. B. Pedersen. 2004. Toxicological studies on lactose oxidase from Microdochium nivale expressed in Fusarium venenatum. Regul. Toxicol. Pharmacol. 39:256-270.

Bafort, F., O. Parisi, J. P. Perraudin, and M. H. Jijakli. 2014. Mode of action of lactoperoxidase as related to its antimicrobial activity: A review. Enzyme Res. 2014:517164.

Barrett, N. E., A. S. Grandison, and M. J. Lewis. 1999. Contribution of the lactoperoxidase system to the keeping quality of pasteurized milk. J. Dairy Res. 66:73-80.

De Jonghe, V., A. Coorevits, K. Van Hoorde, W. Messens, A. Van Landschoot, P. De Vos, and M. Heyndrickx. 2011. Influence of storage conditions on the growth of Pseudomonas species in refrigerated raw milk. Appl. Environ. Microbiol. 77:460-470.

De Wit, J. N., and A. C. M. Van Hooydonk. 1996. Structure, functions and applications of lactoperoxidase in natural antimicrobial systems. Neth. Milk Dairy J. 50:227-244.

Dionysius, D. A., P. A. Grieve, and A. C. Vos. 1992. Studies on the lactoperoxidase system: Reaction kinetics and antibacterial activity using two methods for hydrogen peroxide generation. J. Appl. Bacteriol. 72:146-153.

Dobbenie, D., M. Uyttendaele, and J. Debevere. 1995. Antibacteria activity of the glucose oxidase/glucose system in liquid whole egg. J. Food Prot. 58:273-279.

FAO/WHO (Food and Agriculture Organization of the United Nations/World Health Organization). 1991. Guidelines for Preservation of Raw Milk by Use of the Lactoperoxidase System. FAO/ WHO, Rome, Italy.

FAO/WHO (Food and Agriculture Organization of the United Nations/World Health Organization). 2006. Benefits and Potential Risks of the Lactoperoxidase System of Raw Milk Preservation. $\mathrm{FAO} / \mathrm{WHO}$, Rome, Italy.
Fweja, L. W. T., M. J. Lewis, and A. S. Grandison. 2008. Challenge testing the lactoperoxidase system against a range of bacteria using different activation agents. J. Dairy Sci. 91:2566-2574.

Kozak, S. M., S. Brown, Y. Bobak, and D. J. D'Amico. 2018. Control of Listeria monocytogenes in whole milk using antimicrobials applied individually and in combination. J. Dairy Sci. 101:1889-1900.

Kussendrager, K. D., and A. C. M. van Hooijdonk. 2000. Lactoperoxidase: Physico-chemical properties, occurrence, mechanism of action and applications. Br. J. Nutr. 84(Suppl. 1):S19-S25.

Laurberg, P., I. B. Pedersen, A. Carlé, S. Andersen, N. Knudsen, and J. Karmisholt. 2009. The relationship between thiocyanate and iodine. Pages 275-281 in Comprehensive Handbook of Iodine: Nutritional, Biochemical and Therapeutic Aspects. V. R. Preedy, G. N. Burrow, and R. Watson, ed. Elsevier, Amsterdam, the Netherlands.

Martin, N. H., A. Friedlander, A. Mok, D. Kent, M. Wiedmann, and K. Boor. 2014. Peroxide test strips detect added hydrogen peroxide in raw milk at levels affecting bacterial load. J. Food Prot. 77:1809-1813.

Martin, N. H., K. J. Boor, and M. Wiedmann. 2018. Symposium review: Effect of post-pasteurization contamination on fluid milk quality. J. Dairy Sci. 101:861-870.

Nordkvist, M., P. M. Nielsen, and J. Villadsen. 2007. Oxidation of lactose to lactobionic acid by a Microdochium nivale carbohydrate oxidase: Kinetics and operational stability. Biotechnol. Bioeng. 97:694-707.

Reiter, B., V. M. Marshall, L. Björck, and C. G. Rosén. 1976. Nonspecific bactericidal activity of the lactoperoxidases-thiocyanate-hydrogen peroxide system of milk against Escherichia coli and some gram-negative pathogens. Infect. Immun. 13:800-807.

Schröder, M. J. A. 1984. Origins and levels of post pasteurization contamination of milk in the dairy and their effects on keeping quality. J. Dairy Res. 51:59-67.

Seifu, E., E. M. Buys, and E. F. Donkin. 2005. Significance of the lactoperoxidase system in the dairy industry and its potential applications: A review. Trends Food Sci. Technol. 16:137-154.

Stellato, G., D. R. Utter, A. Voorhis, M. De Angelis, A. M. Eren, and D. Ercolini. 2017. A few Pseudomonas oligotypes dominate in the meat and dairy processing environment. Front. Microbiol. 8:264.

Teh, K. H., S. Flint, J. Palmer, D. Lindsay, P. Andrewes, and P. Bremer. 2011. Thermo-resistant enzyme-producing bacteria isolated from the internal surfaces of raw milk tankers. Int. Dairy J. $21: 742-747$.

Walstra, P., J. T. M. Wouters, and T. J. Geurts. 2005. Dairy Science and Technology. 2nd ed. CRC Press, Boca Raton, FL. 